\title{
Transcriptome analysis of root response to citrus blight based on the newly assembled Swingle citrumelo draft genome
}

\author{
Yunzeng Zhang ${ }^{1}$, Gary Barthe ${ }^{2}$, Jude W. Grosser ${ }^{2}$ and Nian Wang ${ }^{1 *}$
}

\begin{abstract}
Background: Citrus blight is a citrus tree overall decline disease and causes serious losses in the citrus industry worldwide. Although it was described more than one hundred years ago, its causal agent remains unknown and its pathophysiology is not well determined, which hampers our understanding of the disease and design of suitable disease management.

Results: In this study, we sequenced and assembled the draft genome for Swingle citrumelo, one important citrus rootstock. The draft genome is approximately $280 \mathrm{Mb}$, which covers $74 \%$ of the estimated Swingle citrumelo genome and the average coverage is around 15X. The draft genome of Swingle citrumelo enabled us to conduct transcriptome analysis of roots of blight and healthy Swingle citrumelo using RNA-seq. The RNA-seq was reliable as evidenced by the high consistence of RNA-seq analysis and quantitative reverse transcription PCR results $\left(R^{2}=0\right.$. 966). Comparison of the gene expression profiles between blight and healthy root samples revealed the molecular mechanism underneath the characteristic blight phenotypes including decline, starch accumulation, and drought stress. The JA and ET biosynthesis and signaling pathways showed decreased transcript abundance, whereas SA-mediated defense-related genes showed increased transcript abundance in blight trees, suggesting unclassified biotrophic pathogen was involved in this disease.

Conclusions: Overall, the Swingle citrumelo draft genome generated in this study will advance our understanding of plant biology and contribute to the citrus breeding. Transcriptome analysis of blight and healthy trees deepened our understanding of the pathophysiology of citrus blight.
\end{abstract}

Keywords: Citrus blight, Swingle citrumelo, Root, Genome assembly, RNA-seq

\section{Background}

Citrus blight, a citrus tree overall decline disease caused by unknown agent, was first described over 100 years ago [1]. This disease normally occurs in hot and humid citrus-producing areas, including North America, the Caribbean, South America, South Africa and Australia. The typical blight symptoms include zinc deficiency in the leaves, twig die back and overall tree decline [2-5]. Expression of p12 and blockage of xylem tissues are always associated with blight trees [2-5]. Consequently, antibody against p12 and reduced water uptake into the trunk due to the xylem blockage are widely used for

\footnotetext{
*Correspondence: nianwang@ufl.edu

${ }^{1}$ Citrus Research and Education Center, Department of Microbiology and Cell

Science, IFAS, University of Florida, Lake Alfred, FL, USA

Full list of author information is available at the end of the article
}

diagnosis of citrus blight $[6,7]$. The causal agent of citrus blight remains unknown. The symptoms and characteristics associated with citrus blight can be reproduced by root graft inoculations but not by grafting canopy branches or by soil replacement, suggesting that citrus blight is caused by a systemic infectious agent, and the causal agent is restricted to the roots, as reviewed by Derrick and Timmer [5]. However, several observations found the disease spreading behavior fits a linear model, similar to abiotic abnormalities [5]. Multiple plant pathogens, such as Xylella fastidiosa [8], Fusarium solani $[9,10]$ and idaeovirus [11], as well as some abiotic factors, such as nitrogen nutrients [12], were hypothesized as causal agents of citrus blight, but none have been confirmed [5]. 
Plants have integrative signaling and response networks to adapt themselves to the ever-changing environments. For example, when facing drought stress, metabolism is reprogrammed, and the synthesis and signaling pathways of ABA are activated $[13,14]$. When attacked by pathogens, plant immune responses are triggered, leading to dramatic changes in host transcriptional responses. Distinct features of host responses have been reported in response to infection by different pathogens or abiotic stresses $[15,16]$. Therefore, investigation of the host transcription response will deepen our understanding of the pathophysiology and etiology of citrus blight. In a previous study, cDNA subtractive hybridization was used to identify differentially expressed genes in the roots of healthy and blighted rough lemon (Citrus jambhiri Lush) rootstock supporting sweet orange (C. sinensis). However, genome sequence was unavailable for citrus when this study was performed in 2004. Thus, little information was gained in this previous study [17]. Recently, the genomes of sweet orange (C. sinensis) and clementine mandarin $(C$. clementina) have been sequenced and assembled into draft genomes $[18,19]$, which facilitate the assembly and annotation of newly sequenced closely related citrus species. In addition, RNA-seq-based next-generation sequencing allows unprecedented opportunities to identify novel transcripts [20]. Thus, we aimed to revisit the citrus blight with the aid of the citrus genome sequences and next generation sequencing technologies. The draft genome of Swingle citrumelo, a very important rootstock in Florida [21], was sequenced, assembled and used as reference for RNA-seq analysis. More than 4000 differential expressed genes were identified using Tophat-Cufflinks-Cuffdiff pipeline [22], and their association with the citrus blight disease development and adaption was explored. Understanding the pathophysiology of citrus blight will provide hints for novel disease management and disease-resistant breeding improvement.

\section{Results}

\section{Overview of the Swingle citrumelo draft assembly and} annotation

The rootstock used in this study, Swingle citrumelo, is a hybrid from Citrus paradisi Macf. X Poncirus trifoliata (L.) Raf. (synonym: Citrus $\times$ paradisi $\times$ Citrus trifoliate, NCBI taxonomy ID: 309804) [23]. It formed a separate phylogenetic clade from the two published citrus genomes (see Additional file 1: note 4 and Figure S1). To obtain a reliable reference genome for the RNA-seq analysis, the Swingle citrumelo draft genome was assembled based on a reference-assisted approach.

A total of $69,656,379 \times 2$ trimmed high quality pair-end DNA reads (13.6 Gigabases (Gb)), from sample 23_11 were subjected for assembling using CLC genomic workbench v6.0.1 (CLC Bio). The assembly produced by word size 33 contained $720.2 \mathrm{~K}$ contigs with average contig length $669 \mathrm{bp}$ with a total length of $482 \mathrm{Mb}$. After removing low credential contigs (average coverage lower than 6) and non-citrus originated contigs, 136,559 scaffolds affiliated with citrus were combined together, scaffolded and gap filled as mentioned in supplementary files. The resulting assembly length was $280.6 \mathrm{Mb}$, which covered about $74 \%$ of the estimated swingle genome (380 $\mathrm{Mb}$ per $1 \mathrm{C}$ genome) (0.788 pg/2C) [24]. The average coverage was approximately $15 \mathrm{X}$. The assembly has been deposited in NCBI under accession no. AZHM00000000. The detailed assembly information was listed in Table 1.

In total, 446 (97.4\%) of the 458 Core eukaryotic genes (CEGs) were identified in the assembly, and $97.8 \%$ and $96.3 \%$ of the 7954 swingle ESTs were aligned to the assembly using sim $4 \mathrm{db}$ and exonerate, respectively, suggesting the draft assembly has a high coverage of coding sequences.

A total of $44.8 \mathrm{Mb}(16.8 \%$ of $280.6 \mathrm{Mb})$ of repetitive elements were identified in the draft assembly using RepeatMasker, generating a 235.8 Mb repeat-masked assembly for gene prediction. Following two cycles of MAKER run, 29,054 genes were predicted without detection of alternative splicing forms (see Additional file 1: note 3 ). This version of annotation was used as reference for RNA-seq analysis.

\section{Overview of the RNA-seq data}

A total of 725 million high-quality, paired-end reads (approximately $91.8 \%$ of the total raw reads) were generated from the seven root samples from healthy and blight trees after trimming using CLC genomic workbench V6.0.1 (CLC Bio), with 100.8 to 117.6 million reads from each sample. A total of 505.69 million reads (69.8 \% of trimmed reads) could be mapped uniquely to one location within the draft assembly, whereas an additional 6.69 million reads (0.9 \%) were mapped to multiple locations within the draft assembly (Table 2).

Table 1 Overview of the draft assembly of Swingle citrumelo

\begin{tabular}{ll}
\hline Estimated genome size $(\mathrm{Mb})$ & 380 \\
Genome assembly length $(\mathrm{Mb})$ & 280.6 \\
Estimated coverage $(\%)$ & 74 \\
Number of scaffolds ( $\geq 500 \mathrm{bp})$ & 66,319 \\
Largest scaffold $(\mathrm{kb})$ & 234 \\
$\mathrm{~N} 50$ length $(\mathrm{kb})$ & 11.4 \\
$\mathrm{GC}$ content $(\%)$ & 34.44 \\
N's length $(\mathrm{Mb})$ & 14 \\
Repetitive element length $(\mathrm{Mb})$ & 44.8 \\
Gene number & 29,054 \\
\hline
\end{tabular}


Transcriptome analysis of roots of healthy and blight trees The variation between the seven samples was assessed using a multidimensional scaling (MDS) plot based on the overall gene expression profiles prior to differential expression analysis. In the MDS plot, the two healthy trees (20_6 and 24_8) formed a group, the two blight trees (14_14 and 16_11) clustered closely, and the two pre-blight trees (18_7 and 23_11) and the late blight stage tree (20_2) stood alone and were separated from the other trees (Additional file 1: Figure S2). Specifically, the healthy trees remained healthy in a two-year duration, whereas the pre-blight trees showed no obvious blight symptoms at the beginning, but were diagnosed as blight later, Candidatus Liberibacter asiaticus, the causal agent of Huanglongbing was also detected in sample 18_7 but not in other samples.

Plant gene expression can be affected by many factors. The seven samples were collected from the same citrus grove under the same agricultural practices to minimize influence of environmental factors on the differential gene expression between blight and healthy trees. In addition, to rule out the possibility of differential gene expression caused by genetic difference, a phylogenetic tree was constructed using single nucleotide polymorphism (SNP) of the seven samples. SNPs were called by mapping DNA reads from all seven samples to the Swingle citrumelo assembly. The phylogenetic tree revealed the seven samples were nearly identical (Additional file 1: Figure S1). Among the first 10,000 SNP sites, 9995 sites were identical for all seven samples, further demonstrating the samples used were from nucellar seedlings. Thus the possibility of genomic background difference caused by zygotic seedlings was ruled out.

To investigate the differential gene expression between blight and healthy samples, we focused on the two healthy trees (20_6 and 24_8) and two blight trees (14_14 and 16_11), which had more consistent intragroup expression profiles. The two pre-blight samples were not closely grouped, thus eliminated from further analysis due to lack of replication (Additional file 1: Figure S2C). Using a stringent cutoff: 2-fold change, qvalue $\leq 0.05$ and FPKM $\geq 1,4440$ differentially expressed genes (DEGs) including 2383 down-regulated genes and 2057 up-regulated genes (blight vs. healthy), were identified (Additional file 2).

\section{The metabolism pathways overview}

In the down-regulated genes in blight trees, metabolism related GO SLIM terms were enriched, including "biosynthetic process, GO:0009058", "catabolic process, GO:0009056", "lipid metabolic process, GO:0006629", "carbohydrate metabolic process, GO:0005975", "secondary metabolic process, GO:0019748" and "cellular protein modification process, GO:0006464" (Table 3). Further analysis using MapMan indicated that the DEGs involved in the TCA cycle, mitochondrial electron transport, and nitrogen assimilation, and most of the DEGs involved in amino acid metabolism, lipid metabolism, glycolysis, secondary metabolism and nucleotide metabolism, were down-regulated in blight trees (Fig. 1). The downregulation of metabolism genes is consistent with the decline of blight trees.

Although most of the metabolic pathways showed reduced transcription activity in blight trees, the GO term "starch metabolic process, GO:0005982" was enriched with up-regulated genes under blight conditions (Table 3). Furthermore, the MapMan analysis demonstrated that a small subunit of ADP-glucose pyrophosphorylase (XLOC_004663), which catalyzes the first step of starch synthesis, three starch synthases (XLOC_055628, XLOC_021153, XLOC_004226) and a starch branching enzyme (XLOC_011216) were upregulated in blight trees. Numerous genes encoding enzymes involved in starch degradation, including starch cleavage and disproportionation, were also up-regulated in blight trees. A gene encoding sucrose phosphate synthase, responsible for sucrose synthesis, was up-regulated, whereas multiple genes involved in sucrose degradation pathways were down-regulated in blight trees (Fig. 2).

\section{The hormone related genes}

Significant alteration in expression for genes involved in hormone related pathways was observed between the blight and healthy samples. Two genes, XLOC_027196

Table 2 Overview of mapped RNA-seq reads using Tophat2

\begin{tabular}{lcccc}
\hline Sample & Trimmed reads (million) & Unique mapping reads (million) & Multi-mapping reads (million) & Percentage of mapped reads (\%) \\
\hline $14 \_14$ & 117.6 & 82.61 & 1.13 & 71.6 \\
$16 \_11$ & 100.8 & 70.51 & 0.97 & 70.9 \\
$20 \_2$ & 91 & 60.85 & 0.77 & 67.7 \\
$18 \_7$ & 98.8 & 70.31 & 0.90 & 72.1 \\
$20 \_6$ & 105 & 72.12 & 1.00 & 69.6 \\
$23 \_11$ & 107.8 & 76.01 & 1.01 & 71.4 \\
$24 \_8$ & 104.6 & 73.28 & 0.91 & 70.9
\end{tabular}

Note: the data was calculated by RSeQC ver2.3.6 [62] 
Table 3 The enriched GO terms and plant GO SLIM terms in the differentially expressed genes (DEGs) in the blight trees compared to healthy tree revealed by Blast2GO

\begin{tabular}{|c|c|c|c|c|c|c|c|}
\hline GO-ID & Term & FDR & P-Value & \#Test & \#Ref & \#not annot in Test & \#not annot in Ref \\
\hline \multicolumn{8}{|c|}{ Down-regulated plant GO SLIM terms } \\
\hline GO:0009058 & Biosynthetic process & $5.12 \mathrm{E}-05$ & $1.58 \mathrm{E}-06$ & 660 & 5048 & 1241 & 12083 \\
\hline GO:0019748 & Secondary metabolic process & $1.94 \mathrm{E}-04$ & 7.39E-06 & 235 & 1569 & 1666 & 15562 \\
\hline GO:0009056 & Catabolic process & 4.05E-04 & 2.11E-05 & 364 & 2643 & 1537 & 14488 \\
\hline GO:0006629 & Lipid metabolic process & 0.015215 & 0.001265 & 264 & 1964 & 1637 & 15167 \\
\hline GO:0006464 & Cellular protein modification process & 0.017532 & 0.001541 & 271 & 2030 & 1630 & 15101 \\
\hline GO:0005975 & Carbohydrate metabolic process & 0.027641 & 0.002561 & 327 & 2522 & 1574 & 14609 \\
\hline \multicolumn{8}{|c|}{ Up-regulated GO terms } \\
\hline GO:0006075 & (1-> 3)-beta-D-glucan biosynthetic process & 0.013333 & 3.99E-05 & 11 & 22 & 1555 & 17444 \\
\hline GO:0080165 & Callose deposition in phloem sieve plate & 0.034774 & $1.48 \mathrm{E}-04$ & 7 & 9 & 1559 & 17457 \\
\hline GO:0005982 & Starch metabolic process & 0.034774 & $1.54 \mathrm{E}-04$ & 73 & 505 & 1493 & 16961 \\
\hline
\end{tabular}

Note: \#Test: the number of DEGs in the listed gene set; \#Ref: the number of genes belonging to the listed gene set annotated in the Swingle citrumelo genome; \# not annot in Test: the number of DEGs not belonging to the listed gene set; \# not annot in Ref: the number of genes not belonging to the listed gene set annotated in the Swingle citrumelo genome

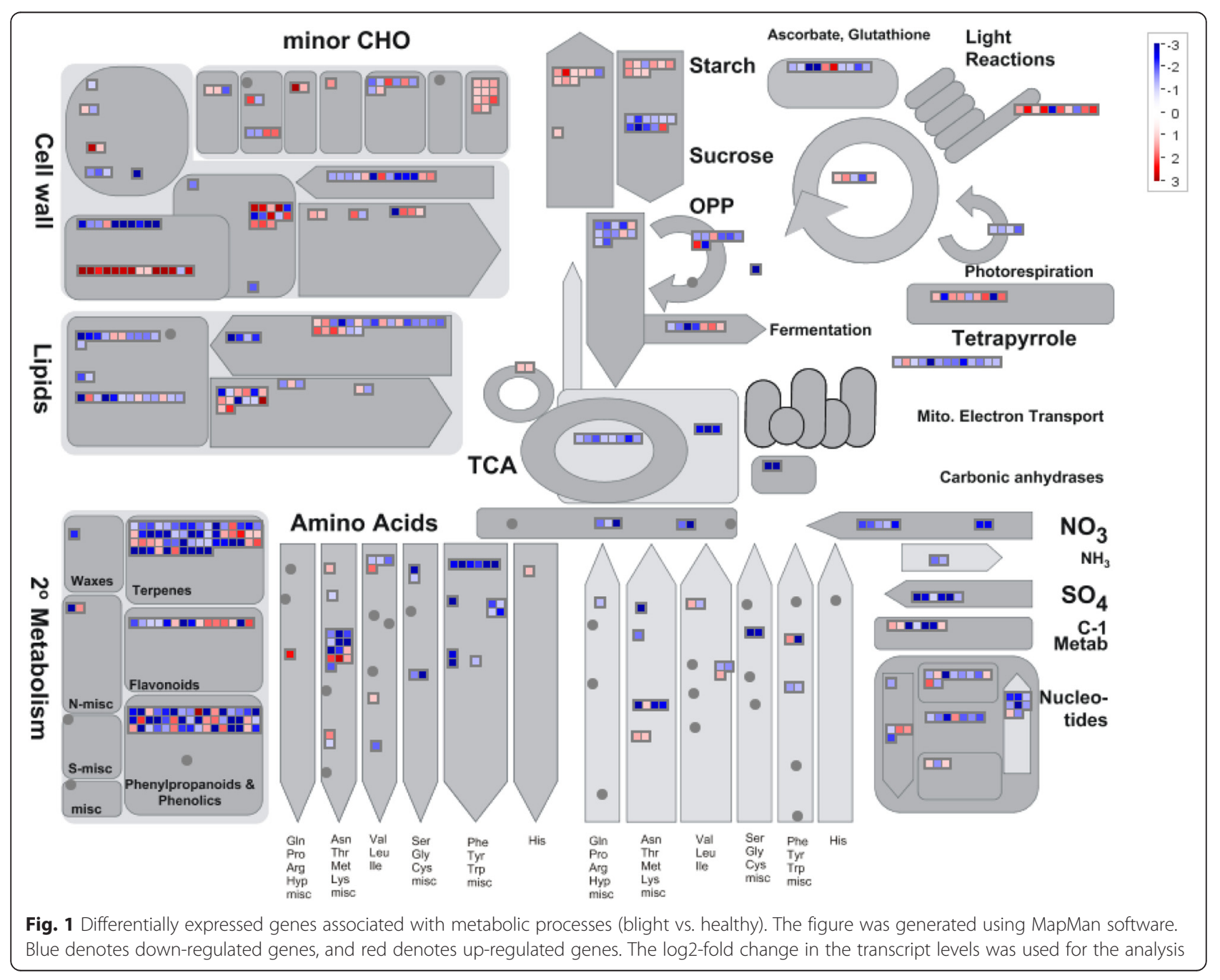




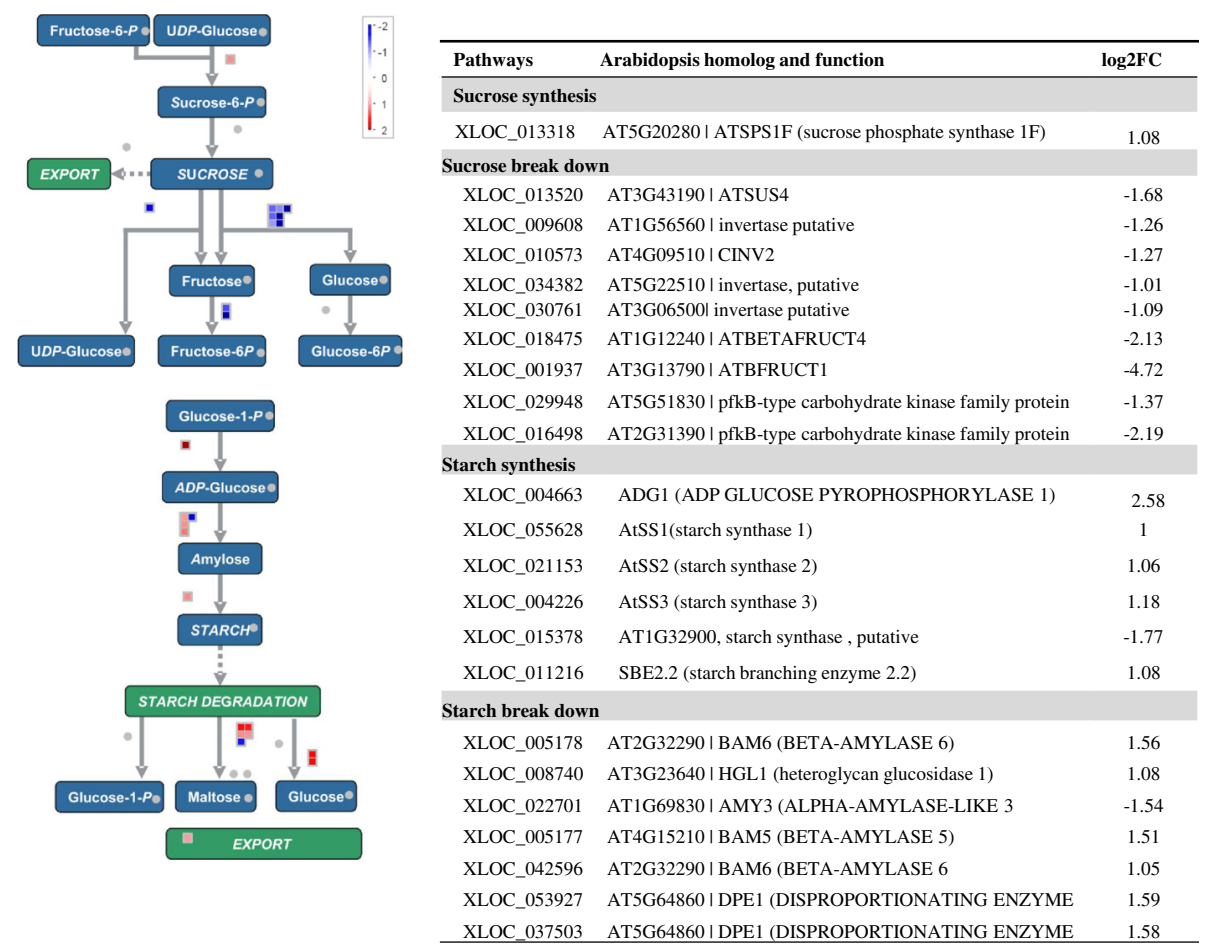

Fig. 2 Differentially expressed genes associated with starch and sucrose metabolism (blight vs. healthy). The figure was generated using MapMan software. Blue denotes down-regulated genes, and red denotes up-regulated genes (Blight vs. Healthy). The log2-fold change in the transcript levels was used for the analysis

and XLOC_027197, which were annotated as homologs of Arabidopsis aldehyde oxidase $1(A A O 1)$ and $A A O 3$, respectively, were up-regulated in blight trees. The $A A O 3$ gene encodes an enzyme that catalyzes the final step of ABA biosynthesis and plays a crucial role in ABA synthesis, whereas the AAO1 gene may contribute partially to ABA biosynthesis [25]. Two ABA3 genes (XLOC_011831 and XLOC_011832), which are the key regulator of ABA biosynthesis, were up-regulated. In addition, XLOC_028331 and XLOC_010730, which encode ABA responsive elements-binding factor 3 (ABF3) and ABF4 respectively, were also induced in blight trees (Additional file 1: Table S1).

Several genes involved in JA synthesis, such as allene oxidase synthase, allene oxidase cyclase and 12-OxoPDA-reductase genes, were down-regulated in blight trees (Fig. 3). Down-regulation of the ethylene synthesis genes 1-aminocyclopropane-1-carboxylate oxidase (ACO) gene ACO1 (XLOC_012043) and ACO4 (XLOC_004937) was observed in blight trees. Furthermore, the ethylene responsive factors (ERFs), including ERF1, the crucial defense signaling factor for JA and ethylene signaling pathway, were down-regulated in blight trees (Additional file 1: Table S1).

\section{The plant defense system}

Two GO terms, (1->3)-beta-D-glucan biosynthetic process (GO:0006075) and callose deposition in phloem sieve plate (GO: 0080165), with 11 genes included, were enriched in the blight up-regulated gene set (Table 3), and all the 11 genes were annotated as glucan synthaselike (Gsl) genes (also known as callose synthase (Cals) genes).

The mitogen-activated protein kinase gene MPK4 (XLOC_037129) and its upstream activator mitogenactivated protein kinase kinase (MKK) gene MKK2 [26] (XLOC_012257) were down-regulated in blight trees. MPK4 is known as a negative regulator of SA-dependent systemic acquired resistance as well as a positive regulator of ET and JA mediated defense [27, 28]. The downregulation of MPK4 suggests that the JA and ET-related pathways were repressed, whereas the SA-related defense pathways were activated in blight trees. In fact, the JA and ET synthesis and signaling pathways were down-regulated (see above); in contrast, several SAinduced genes showed increased transcript abundance in blight trees. The NPR1 (nonexpresser of PR genes 1) (XLOC_012174, q-value $=0.038, \log 2 \mathrm{FC}=0.93)$, which plays a key role in the SA-mediated defense signaling pathways, was up-regulated. NPR3 (XLOC_022440) and NPR4 (XLOC_022463 and XLOC_022469), which act as adaptor proteins for CUL3 E3 ligase to degrade NPR1 specifically [29], were down-regulated in blight trees. In addition, expression of the downstream pathogenesisrelated (PR) gene PR1 (XLOC_026451) and MPK3 


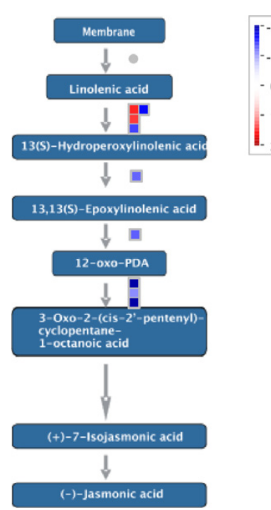

$\begin{array}{llc}\text { Gene name } & \text { Arabidopsis homolog and function } & \log 2 \text { FC) } \\ \text { XLOC_001819 } & \text { AT1G72520 llipoxygenase, putative } & 1.50 \\ \text { XLOC_001826 } & \text { AT1G17420| LOX3 } & 1.42 \\ \text { XLOC_038408 } & \text { AT3G45140| LOX2 } & -1.39 \\ \text { XLOC_031698 } & \text { AT1G72520 llipoxygenase, putative } & -1.59 \\ \text { XLOC_005011 } & \text { AT5G42650lallene oxidase synthase } & -1.25 \\ \text { XLOC_025763 } & \text { AT3G25780 lallene oxidase cyclase } & -1.28 \\ \text { XLOC_015414 } & \text { AT1G76680 I12-Oxo-PDA-reductase } & -2.17 \\ \text { XLOC_012299 } & \text { AT2G06050 I12-Oxo-PDA-reductase } & -1.08 \\ \text { XLOC_038293 } & \text { AT1G76690|12-Oxo-PDA-reductase } & -5.14\end{array}$

Fig. 3 The JA synthesis pathway was repressed in blight trees. Blue denotes down-regulated genes, and red denotes up-regulated genes (Blight vs. Healthy). The figure was generated using MapMan software. The log2-fold change in the transcript levels was used for the analysis

(XLOC_027731) was up-regulated in blight trees. Upregulation of three SA-related WRKY transcription factors, WRKY33 (XLOC_019616), WRKY53 (XLOC_037606) and WRKY70 (XLOC_019719) and a gene encoding glutaredoxin (XLOC_004271) was also observed.

\section{RT-qPCR validation of differentially expressed genes from RNA-seq}

Twenty-five genes in the DEGs, including 11 downregulated and 14 up-regulated genes, were selected for RT-qPCR assay to validate the RNA-seq results (Fig. 4 and Additional file 1: Table S2). As shown in Fig. 4, the RT-qPCR results suggested that the expression patterns of these genes were consistent with the RNA-seq data $\left(R^{2}=0.966\right)$.

\section{Discussion}

Eight citrus cultivars have been sequenced, and two of them, sweet orange (Citrus sinensis) and C. clementina, were assembled to draft genomes [18, 19]. Swingle citrumelo was sequenced and assembled in this study. Swingle citrumelo is the most important rootstock in Florida, accounting for $37 \%$ of all propagations as of 2012 [21]. Swingle citrumelo is a hybrid from Citrus paradisi Macf. X Poncirus trifoliata (L.) Raf. [23]. The phylogenetic tree, which was constructed using the

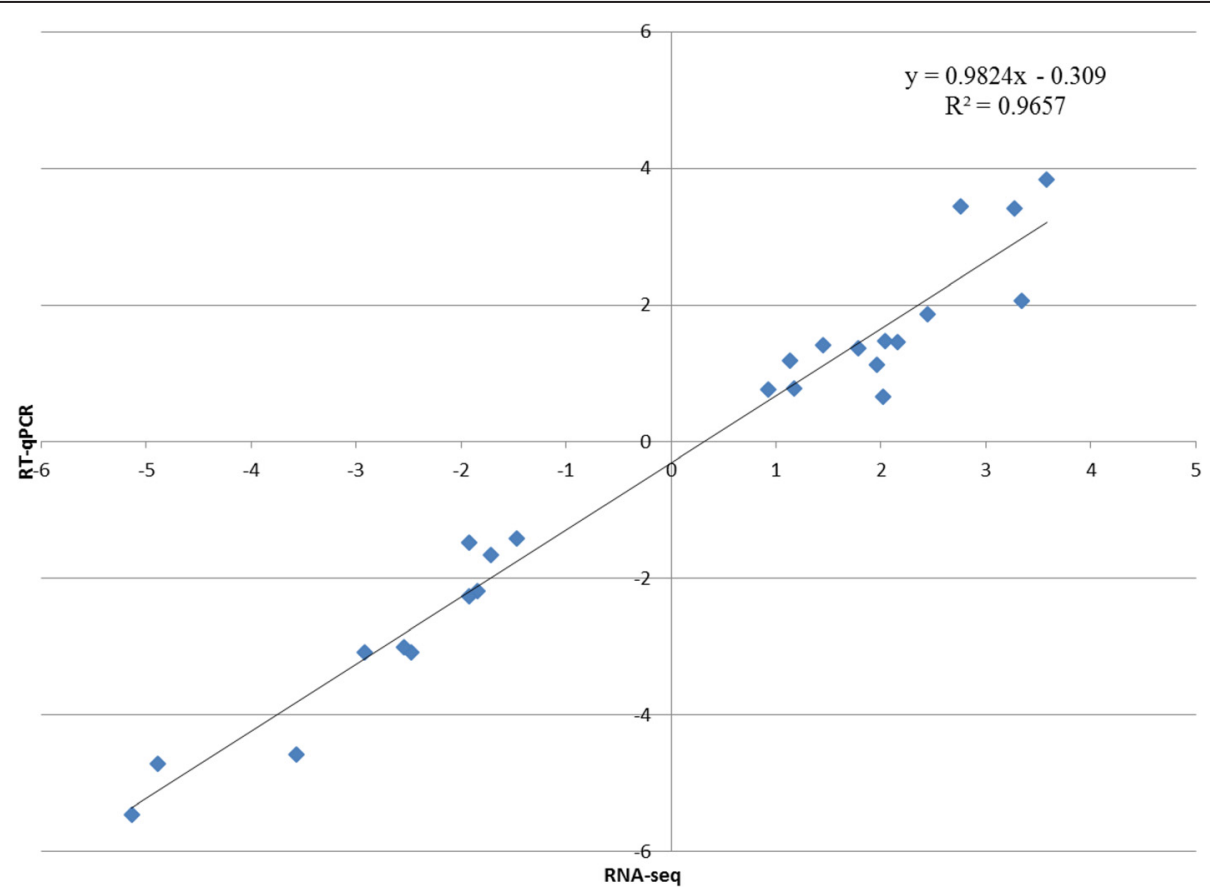

Fig. 4 RT-qPCR validation of differentially expressed genes. The log2FC values from the RNA-seq results are displayed on the $x$-axis, and the values from the RT-qPCR are displayed on the $y$-axis. The high $R^{2}(0.966)$ indicates the results from the RT-qPCR and RNA-seq are consistent 
SNPhylo pipeline [30], demonstrated that Swingle citrumelo formed a separate clade from the clade containing the two published citrus genomes (see Additional file 1: note 4 and Figure S1). Given the high variability of citrus cultivars, mainly due to hybridization during their complex evolutionary history [19], it was crucial to assemble the Swingle citrumelo genome to obtain a reliable annotation for RNA-seq analysis. The high consistence between RNA-seq and RT-qPCR results demonstrated the reliability of the assembly. The Swingle citrumelo draft genome will advance our understanding of plant biology and contribute to the citrus breeding.

Transcriptome analysis of blight and healthy citrus plants provides insights to the molecular mechanism to the characteristic blight phenotypes. Firstly, the GO enrichment analysis and MapMan metabolism overview results demonstrated that many metabolism pathways were down-regulated in the roots of blight trees. The reduced metabolism in the roots is consistent with the overall decline of blight trees since roots are critical for plants to absorb water and nutrition (e.g., nitrogen and mineral elements). Secondly, the expression pattern of starch related genes is in agreement with the observation of a large number of starch grains in the parenchyma cells of the phloem [31]. Furthermore, the gene expression pattern of blight trees is consistent with the drought stress due to xylem blockage [6]. Starch synthesis genes were upregulated in blight trees (Fig. 2), leading to starch deposition. Accumulation of starch has been suggested to help plants adapt to drought stress [32]. ABA also plays a key role in adaptive responses to drought stress [14]. Droughtmediated, up-regulation of ABA synthesis and ABAinduced downstream genes are widely reported [13, 33, 34]. Numerous genes involved in ABA synthesis and signaling showed increased transcript abundance in blight trees including ABA3, AAO1, AAO3, ABF3 and ABF4. AAO3 plays a key role in catalyzing the last step of the ABA synthesis pathway to help plants adapt to drought stress, which has been determined in leaves and seeds [25, $35]$, and this gene is actively expressed in many tissues, including roots, stems and leaves [36]. Consistently, members of the $\mathrm{ABF}$ gene family function in $\mathrm{ABA}$ signaling and can be induced under abiotic stresses, including drought stress [13, 37-39].

Plant hormones play key roles in regulating immune responses to a wide range of pathogens. Among them, SA, JA and ET (ethylene) are the most prominent. SA signaling triggers resistance against biotrophic and hemibiotrophic pathogens; in contrast, JA and ET work together to play an important role in defense against necrotrophs [40, 41]. SA-mediated and JA- and/or ET-dependent defense pathways antagonize each other, and cooperation between them is not commonly observed
$[15,42]$. Our RNA-seq results suggested the JA and ET biosynthesis pathways including ERF1 and ERF2 [43, 44], were down-regulated in blight trees (Fig. 3). ERF proteins are responsible for regulating the expression of JA- and ET-mediated disease resistance response genes by binding to the GCC box (AGCCGCC) in their promoter regions [45]. Two known important positive regulators of JA- and ET- dependent, defense-related transcription, were identified in the down-regulated genes, suggesting the JA and ET-mediated immune systems were repressed in blight trees. On the other hand, up-regulation of NPR1, the central regulator of SA-dependent gene activation and SAR [46], and down-regulation of NPR3 and NPR4, which work as adapters for NPR1 degradation [29], as well as the up-regulation of downstream defense genes (e.g., PR1 and MPK3), indicated that the SA-mediated defense system was activated. The down-regulation of MPK4, which acts as a negative regulator of SA signaling and a positive regulator of JA signaling [28], as well as the up-regulation of glutaredoxin gene, which can be induced by SA and suppresses JA-responsive PDF1.2 transcription [47], further supported our notion. Furthermore, callose $((1,3)-\beta$-glucan polymer) synthesis and deposition can play an important role in the defense response to invading pathogens $[48,49]$. We observed the induction of 11 CalS genes in blight diseased trees (Table 3). In Arabidopsis, the expression of CalS1 (Gsl-6) and CalS2 (Gsl-3) is NPR1dependent [50]. The induction of SA-dependent defense genes and the repression of JA- and ET-mediated immune systems supported the proposition that a systemic infectious agent, probably an unidentified biotrophic pathogen, is involved in citrus blight, as suggested by Derrick and Timmer [5]. However, given the fact that the plant hormone signaling pathways are well programmed by plant to respond to both biotic and abiotic stresses, the possibility of certain abiotic stress contributed to the observed antagonism between JA-ET dependent and SA mediated signaling pathways could not be ruled out [51].

\section{Conclusions}

In conclusion, we have sequenced and assembled the draft genome of Swingle citrumelo. We also analyzed the root transcriptome of blight and healthy trees. The transcriptome analysis provides insights to the molecular mechanism underneath the characteristic blight phenotypes including decline, starch accumulation, and drought stress. The activation of SA-dependent defense pathways and the repression of JA- and ET- mediated defense pathways were observed in blight trees, further supporting that unidentified biotrophic pathogen(s) was/were involved in citrus blight. This study deepened our understanding of the pathophysiology of citrus blight. However, the causal agent remains undetermined and yet to be determined. 


\section{Methods}

Plant materials, nucleic acid extraction and sequencing

Sweet orange on Swingle citrumelo [Citrus paradise Macf. $\times$ Poncirus trifoliata (L.) Raf.] (synonym: Citrus $\times$ paradisi $\times$ Citrus trifoliate, NCBI taxonomy ID: 309804) rootstock in a citrus grove located at St. Cloud (28 ${ }^{\circ} 15^{\prime}$ $\mathrm{N}, 81^{\circ} 14^{\prime} \mathrm{W}$ ) was selected to collect root samples from healthy and blight trees. These trees were approximately 20 years old. The trees were diagnosed as blight-diseased based on visual symptoms, the p12 immunoassay on leaf tissues (Additional file 1: Figure S2), and water uptake results $[6,7]$. The trees were followed for two years for disease development after sampling. Based on initial and later diagnoses, the trees were classified as healthy (2 trees, 20_6 and 24_8, water uptake $>20 \mathrm{ml} / 30 \mathrm{~s}$ in all tests during the two years period), pre-blight (2 trees, 18 -7 and 23_11, healthy when collected samples but diagnosed as blight one year after the initial diagnosis, water uptake $>20 \mathrm{ml} / 30 \mathrm{~s}$ for the initial survey but $<5 \mathrm{ml} / 30 \mathrm{~s}$ for the second survey), blight ( 2 trees, 14_14 and 16_11, water uptake $=0 \mathrm{ml} / 30 \mathrm{~s}$ for two years tests) and late-blight (1 tree, 20_2, the symptoms were very severe at one year after the initial diagnosis) (Additional file 1: Figure S2). Around $10 \mathrm{~cm}$ lateral root segments (diameter approximately $0.5 \mathrm{~cm}$ ) were collected from four corners of one tree and were pooled together. Two root segments from two individual lateral roots were harvested from each corner and eight segments were collected for each tree. The rhizosphere soil was removed, and roots were cleaned by repeated washing (3 rinses) using pre-cooled $\mathrm{dd}_{2} \mathrm{O}$. Then, the roots were flash-frozen in liquid nitrogen. All the steps were performed on site. When back to laboratory, the frozen materials were stored at $-80{ }^{\circ} \mathrm{C}$ until use. The woody part was removed with pre-cooled knife, and the remaining part of the roots was grounded to a homogenous powder using a sterilized mortar and pestle and liquid nitrogen.

Total RNA was extracted using the RNeasy plant mini kit, and contaminating genomic DNA was removed by performing the following On-column DNase digestion step, according to the manufacturer's protocol (Qiagen). The integrity of the RNA was verified on an Agilent RNA6000 Pico Chip. Plant ribosomal RNA was depleted using the Ribo-Zero ${ }^{\text {тм }}$ Magnetic kit (PNMRZSR116) according to the manufacturer's instructions (Epicenter Technologies). The RNA-Seq libraries were prepared using the Script Seq v2 RNA-Seq library preparation kit (Epicenter Technologies). Total DNA was extracted using the DNeasy plant maxi kit (Qiagen). DNA libraries were prepared through a semi-automated procedure using a Beckman Coulter SPRI-TE ${ }^{\mathrm{m}}$ workstation. The RNA and DNA samples were sequenced on an Illumina HiSeq 2000 platform for 101 cycles in both directions.
Swingle citrumelo draft genome assembly and annotation The $81,496,678 \times 2$ paired-end raw DNA reads from tree 23_11 were trimmed using CLC genomic workbench (V6.0.1, CLC Bio) with the following the parameters: minimum quality score 0.05 , maximum number of ambiguities 2 and discarding the reads containing adapters or reads shorter than 55 bp. A total of $69,656,379 \times 2$ high quality paired-end reads with average length 97.6 bp were kept and were assembled using CLC genomic workbench (V6.0.1, CLC Bio) with an iterative adaptive assembly approach with a range of word sizes. The contigs generated by the assembly of word size 33 were chosen for further analysis because a word size of 33 produced the longest (on average) contigs and the highest matched reads. The citrus-originated contigs were extracted, scaffolded and gap-filled using a referencebased approach [18]. The completeness and accuracy of the coding region of the draft assembly were validated using the Core Eukaryotic Genes Mapping Approach (CEGMA) [52] as well as EST mapping using sim4db and exonerate $[53,54]$, respectively. The annotation of this draft genome was created using MAKER2 pipeline [55]. The detailed genome assembly and annotation pipeline are listed in the Additional file 1: notes 1-3.

\section{Differential expression analysis}

The differential gene expression between healthy and blight citrus samples was analyzed following the tuxedo pipeline [22]. In brief, the RNA-seq reads were trimmed as described above. The trimmed reads were mapped to the Swingle citrumelo draft assembly using Tophat2 (ver. 2.0.7), and the generated alignments were fed to Cufflinks (ver. 2.1.1) for transcript assembly. The assemblies from individual samples were merged with the annotation set generated by MAKER2 using Cuffmerge. Gene differential expression analysis was performed using Cuffdiff2 [56], the two healthy trees (20_6 and 24_8) and two blight trees (14_14 and 16_11) were used in the analysis and group-wise comparison was conducted. The results were explored using CummeRbund (http://compbio.mit.edu/cummeRbund/). Only genes fitting the following cutoff: $\mid$ fold change $\mid \geq 2$, q-value $\leq 0.05$ and FPKM $\geq 1$, were considered as significantly differentially expressed genes (DEGs).

The GO terms and plant GO SLIM terms were assigned to the annotated genes of the Swingle citrumelo assembly, and the gene set enrichment analysis of the DEGs was conducted using Blast2GO pipeline [57]. The GO terms and the plant GO SLIM terms were assigned to transcripts based on the b2gsep13 GO database. The up-regulated and down-regulated DEG transcript lists were used as input for the one-tailed Fisher's Exact Test in Blast2GO to identify the enriched GO terms. In addition, the MapMan gene functional categories (Bins) 
were assigned to DEGs using Mercator [58], and differentially regulated bins were identified using MapMan [59].

\section{RT-qPCR analysis}

Total RNA from the same samples used for RNA-seq was reverse-transcribed to cDNA with oligo $(\mathrm{dT})_{20}$ primer using the SuperScript III First Strand Synthesis System (Invitrogen, Life Technologies). The gene expression patterns of FBOX, SAND, GAPC2 (GAPDH) and UPL7, which are recommended as superior reference genes by Mafra et al. [60], were checked from the Cuffdiff result, and GAPC2 was chosen as the reference gene because of its high and constant expression level in our samples. The primers for the target genes (Additional file 1: Table S3) were designed using the Primer3 (Ver. 0.4.0) online tool (http://bioinfo.ut.ee/primer3-0.4.0/). For each primer set, cDNA corresponding to $10 \mathrm{ng}$ of total RNA was subjected to qPCR using a QuantiTect SYBR Green PCR Kit (Qiagen). The qPCR was performed on an Applied Biosystems 7500 fast Real-Time PCR System (Life Technologies). The PCR thermal cycling conditions were as follows: an initial step at $95{ }^{\circ} \mathrm{C}$ for $15 \mathrm{~min}$ and 40 cycles of $15 \mathrm{~s}$ at $95{ }^{\circ} \mathrm{C}, 30 \mathrm{~s}$ at $55{ }^{\circ} \mathrm{C}$ and $30 \mathrm{~s}$ at $72{ }^{\circ} \mathrm{C}$. The signal was collected at the $72{ }^{\circ} \mathrm{C}$ step. The $\Delta \Delta \mathrm{C}_{\mathrm{t}}$ method [61] was used to analyze the results.

\section{Additional files}

Additional file 1: Supplementary figures 1 and 2, supplementary tables 1-4 and supplementary notes for genome assembly, annotation and phylogenetic tree construction. (Word, 1.2 Mb). Including Figure S1. The citrus phylogenetic tree constructed with SNP data from Swingle citrumelo (this study) and 8 citrus cultivars by SNPhylo (page 2); Figure $\mathbf{S 2}$. Analysis of citrus trees used for transcriptome analysis; Table S1. Differentially expressed genes related to ERFs and ABA pathways annotated by MapMan; Table S2. The qRT-PCR validation values for the 25 selected genes; Table S3. Primer sequences used to amplify the selected genes; Table S4. The NCBI accession no. for DNA and RNA reads as well as the draft assembly. (DOCX $1250 \mathrm{~kb}$ )

Additional file 2: All the DEGs identified by cuffdiff2 when cutoff $|F C|>$ $=2, F D R<=0.05$ and FPKM $>=1$ was applied. (XLSX $270 \mathrm{~kb}$ )

\section{Abbreviations}

ABA, Abscisic acid; CB, citrus blight; ET, ethylene; FPKM, Fragments Per Kilobase of transcript per Million mapped reads; JA, Jasmonic acid; SA, Salicylic acid

\section{Funding}

This study has been supported by Florida Citrus Research and Development Foundation.

\section{Availability of data and materials}

The assembled contigs, the DNA reads and the RNA reads from the seven samples were deposited in GenBank under the bioproject accession no. PRJNA224728, and the detailed information is listed in Additional file 1: Table S4. The phylogenetic data: http://purl.org/phylo/treebase/phylows/study/ TB2:S19307.

\section{Authors' contributions}

NW and JG planned and supervised the study. YZ and GB performed the disease diagnostic analysis and collected the samples. YZ performed the genome assembly and RNA-seq analysis and RT-qPCR validation. NW and YZ drafted the manuscript. NW wrote the final version. All authors read and approved the final manuscript.

\section{Competing interests}

The authors declare that they have no competing interests.

\section{Consent for publication}

Not applicable.

\section{Ethics approval and consent to participate}

Not applicable.

No permissions and/or licences is required since citrus is not an endangered species.

\section{Author details}

${ }^{1}$ Citrus Research and Education Center, Department of Microbiology and Cell Science, IFAS, University of Florida, Lake Alfred, FL, USA. ${ }^{2}$ Citrus Research and Education Center, Department of Horticultural Sciences, University of Florida, Lake Alfred, FL, USA.

Received: 15 December 2015 Accepted: 26 May 2016

Published online: 08 July 2016

\section{References}

1. Swingle WT, Webber HJ. The principal disease of citrus fruits in Florida. USDA Div Veg Physiol Pathol Bull. 1896:8:9-14.

2. Albrigo $L G$, Young RH. Phloem zinc accumulation in citrus trees affected with blight. HortSci. 1981;16(2):158-60.

3. Cohen M, Pelosi RR, Brlansky RH. Nature and location of xylem blockage structures in trees with citrus blight. Phytopathology. 1983;73(5):1125-30.

4. Derrick KS, Lee RF, Brlansky RH, Timmer LW, Hewitt BG, Barthe GA. Proteins associated with citrus blight. Plant Dis. 1990;74(2):168-70.

5. Derrick KS, Timmer LW. Citrus blight and other diseases of recalcitrant etiology. Annu Rev Phytopathol. 2000;38:181-205.

6. Lee RF, Marais $L$, Timmer LW, Graham JH. Syringe injection of water into the trunk-a rapid diagnostic test for citrus blight. Plant Dis. 1984;68(6):511-3.

7. Derrick KS, Barthe GA, Hewitt BG, Lee RF, Albrigo LG. Detection of citrus blight by serological assays. Proc Fla State Hort Soc. 1992;105:26-8.

8. Hopkins DL. Production of diagnostic symptoms of blight inoculated with Xylella fastidiosa. Plant Dis. 1988;72(5):432-5.

9. Graham JH, Timmer LW, Young RH. Necrosis of major roots in relation to citrus blight. Plant Dis. 1983;67(11):1273-6.

10. Graham JH, Brlansky RH, Timmer LW, Lee RF, Marais $\sqcup$, Bender GS. Comparison of citrus tree declines with necrosis of major roots and their association with Fusarium solani. Plant Dis. 1985;69(12):1055-8.

11. Derrick KS, Beretta MJ, Barthe GA, Florida State Horticultural S. Detection of an Idaeovirus in citrus with implications as to the cause of citrus blight. Proc Fla Hort Soc. 2006:119:69-72.

12. Wutscher HK, Hardesty CA. Ammonium, nitrite, and nitrate nitrogen levels in the soil under blight-affected and healthy citrus trees. Commun Soil Sci Plant Anal. 1979;10(12):1495-503.

13. Shinozaki K, Yamaguchi-Shinozaki K. Gene networks involved in drought stress response and tolerance. J Exp Bot. 2007;58(2):221-7.

14. Cutler SR, Rodriguez PL, Finkelstein RR, Abrams SR. Abscisic Acid: emergence of a core Signaling network. Annu Revf Plant Biol. 2010;61:651-79

15. Derksen H, Rampitsch C, Daayf F. Signaling cross-talk in plant disease resistance. Plant Sci. 2013;207:79-87.

16. Robert-Seilaniantz A, Grant M, Jones JDG. Hormone crosstalk in plant disease and defense: more than just JASMONATE-SALICYLATE antagonism. Annu Rev Phytopathol. 2011:49:317-43.

17. Carlos EF. Transcriptional profiling on trees affected by citrus blight and identification of an etiological contrast potentially associated with the disease. PhD thesis. Gainesville: University of Florida; 2004.

18. Xu Q, Chen L-L, Ruan X, Chen D, Zhu A, Chen C, Bertrand D, Jiao W-B, Hao B-H, Lyon MP et al. The draft genome of sweet orange (Citrus sinensis). Nat Genet. 2013;45(1):59-66.

19. Wu GA, Prochnik S, Jenkins J, Salse J, Hellsten U, Murat F, Perrier X, Ruiz M, Scalabrin $S$, Terol J, et al. Sequencing of diverse mandarin, pummelo and orange genomes reveals complex history of admixture during citrus domestication. Nat Biotechnol. 2014;32(7):656-62. 
20. Haas BJ, Papanicolaou A, Yassour M, Grabherr M, Blood PD, Bowden J, Couger MB, Eccles D, Li B, Lieber $M$, et al. De novo transcript sequence reconstruction from RNA-seq using the Trinity platform for reference generation and analysis. Nat Protoc. 2013;8(8):1494-512.

21. Putnam A, Gaskalla R, Dixon WMK. Annual Report, Florida citrus budwood protection program. Winter Haven, FL: Bureau of Citrus Budwood Registration; 2012.

22. Trapnell C, Roberts A, Goff L, Pertea G, Kim D, Kelley DR, Pimentel H, Salzberg SL, Rinn JL, Pachter L. Differential gene and transcript expression analysis of RNA-seq experiments with TopHat and Cufflinks. Nat Protoc. 2012;7(3):562-78.

23. Hutchison D. Swingle citrumelo-a promising rootstock hybrid. Proc Fla State Hort Soc. 1974;87:89-91.

24. Seker M, Tuzcu O, Ollitrault P. Comparison of nuclear DNA content of citrus rootstock populations by flow cytometry analysis. Plant Breed. 2003;122(2):169-72.

25. Seo M, Aoki H, Koiwai H, Kamiya Y, Nambara E, Koshiba T. Comparative studies on the Arabidopsis aldehyde oxidase (AAO) gene family revealed a major role of $A A O 3$ in ABA biosynthesis in seeds. Plant Cell Physiol. 2004:45(11):1694-703.

26. Qiu J-L, Zhou L, Yun B-W, Nielsen HB, Fiil BK, Petersen K, MacKinlay J, Loake GJ, Mundy J, Morris PC. Arabidopsis mitogen-activated protein kinase kinases MKK1 and MKK2 have overlapping functions in defense signaling mediated by MEKK1, MPK4, and MKS1. Plant Physiol. 2008;148(1):212-22.

27. Brodersen P, Petersen M, Nielsen HB, Zhu S, Newman M-A, Shokat KM, Rietz S, Parker J, Mundy J. Arabidopsis MAP kinase 4 regulates salicylic acid- and jasmonic acid/ethylene-dependent responses via EDS1 and PAD4. Plant J. 2006;47(4):532-46

28. Petersen $M$, Brodersen $P$, Naested $H$, Andreasson $E$, Lindhart $U$, Johansen B, Nielsen HB, Lacy M, Austin MJ, Parker JE, et al. Arabidopsis MAP kinase 4 negatively regulates systemic acquired resistance. Cell. 2000;103(7):1111-20.

29. Fu ZQ, Yan S, Saleh A, Wang W, Ruble J, Oka N, Mohan R, Spoel SH, Tada Y, Zheng N, et al. NPR3 and NPR4 are receptors for the immune signal salicylic acid in plants. Nature. 2012;486(7402):228-32.

30. Lee TH, Guo H, Wang X, Kim C, Paterson AH. SNPhylo: a pipeline to construct a phylogenetic tree from huge SNP data. BMC Genomics. 2014;15: 162.

31. Lindbeck AGC, Brlansky RH. Cytology of fibrous roots from citrus blightaffected trees. Plant Dis. 2000;84(2):164-7.

32. Cuellar-Ortiz SM, De la Paz A-MM, Acosta-Gallegos J, Covarrubias AA Relationship between carbohydrate partitioning and drought resistance in common bean. Plant Cell Environ. 2008:31(10):1399-409.

33. Molina C, Rotter B, Horres R, Udupa SM, Besser B, Bellarmino L, Baum M, Matsumura $H$, Terauchi $R$, Kahl G, et al. SuperSAGE: the drought stress-responsive transcriptome of chickpea roots. BMC Genomics. 2008; 9:553.

34. Wilkins O, Braeutigam K, Campbell MM. Time of day shapes Arabidopsis drought transcriptomes. Plant J. 2010;63(5):715-27.

35. Seo M, Peeters AJM, Koiwai H, Oritani T, Marion-Poll A, Zeevaart JAD, Koornneef M, Kamiya Y, Koshiba T. The Arabidopsis aldehyde oxidase 3 (AA03) gene product catalyzes the final step in abscisic acid biosynthesis in leaves. Proc Natl Acad Sci U S A. 2000:97(23):12908-13.

36. Koiwai H, Nakaminami K, Seo M, Mitsuhashi W, Toyomasu T, Koshiba T. Tissue-specific localization of an abscisic acid biosynthetic enzyme, $A A O 3$, in Arabidopsis. Plant Physiol. 2004;134(4):1697-707.

37. Fujita Y, Fujita M, Satoh R, Maruyama K, Parvez MM, Seki M, Hiratsu K, Ohme-Takagi M, Shinozaki K, Yamaguchi-Shinozaki K. AREB1 is a transcription activator of novel ABRE-dependent ABA signaling that enhances drought stress tolerance in Arabidopsis. Plant Cell. 2005;17(12):3470-88.

38. Choi HI, Hong JH, Ha JO, Kang JY, Kim SY. ABFs, a family of ABA-responsive element binding factors. J Biol Chem. 2000;275(3):1723-30.

39. Fujita Y, Fujita M, Shinozaki K, Yamaguchi-Shinozaki K. ABA-mediated transcriptional regulation in response to osmotic stress in plants. J Plant Res. 2011;124(4):509-25.

40. Spoel SH, Johnson JS, Dong X. Regulation of tradeoffs between plant defenses against pathogens with different lifestyles. Proc Natl Acad Sc U S A. 2007;104(47):18842-7.

41. Glazebrook J. Contrasting mechanisms of defense against biotrophic and necrotrophic pathogens. Annu Rev Phytopathol. 2005;43:205-27.
42. Pieterse CMJ, Van der Does D, Zamioudis C, Leon-Reyes A, Van Wees SCM. Hormonal modulation of plant immunity. Annu Rev Cell Dev Biol. 2012;28:489-521.

43. Lorenzo O, Piqueras R, Sanchez-Serrano JJ, Solano R. ETHYLENE RESPONSE FACTOR1 integrates signals from ethylene and jasmonate pathways in plant defense. Plant Cell. 2003;15(1):165-78.

44. McGrath KC, Dombrecht B, Manners JM, Schenk PM, Edgar Cl, Maclean DJ, Scheible WR, Udvardi MK, Kazan K. Repressor- and activator-type ethylene response factors functioning in jasmonate signaling and disease resistance identified via a genome-wide screen of Arabidopsis transcription factor gene expression. Plant Physiol. 2005;139(2):949-59.

45. Ohmetakagi M, Shinshi H. Ethylene-inducible DNA-binding proteins that interact with an ethylene-responsive element. Plant Cell. 1995;7(2):173-82.

46. Cao H, Glazebrook J, Clarke JD, Volko S, Dong XN. The Arabidopsis NPR1 gene that controls systemic acquired resistance encodes a novel protein containing ankyrin repeats. Cell. 1997;88(1):57-63.

47. Ndamukong I, Al Abdallat A, Thurow C, Fode B, Zander M, Weigel R, Gatz C. SA-inducible Arabidopsis glutaredoxin interacts with TGA factors and suppresses JA-responsive PDF1.2 transcription. Plant J. 2007;50(1):128-39.

48. Blumke A, Somerville SC, Voigt CA. Transient expression of the Arabidopsis thaliana callose synthase PMR4 increases penetration resistance to powdery mildew in barley. Adv Biosci Biotechnol. 2013:4(8):810-3.

49. Ellinger D, Naumann M, Falter C, Zwikowics C, Jamrow T, Manisseri C, Somerville SC, Voigt CA. Elevated early callose deposition results in complete penetration resistance to Powdery mildew in Arabidopsis. Plant Physiol. 2013;161(3):1433-44.

50. Dong X, Hong Z, Chatterjee J, Kim S, Verma DPS. Expression of callose synthase genes and its connection with NPR1 signaling pathway during pathogen infection. Planta. 2008;229(1):87-98.

51. Atkinson $N$, Urwin P. The interaction of plant biotic and abiotic stresses: from genes to the field. J Exp Bot. 2012;63(10):3523-43.

52. Parra G, Bradnam K, Korf I. CEGMA: a pipeline to accurately annotate core genes in eukaryotic genornes. Bioinformatics. 2007;23(9):1061-7.

53. Walenz B, Florea L. Sim4db and Leaff: utilities for fast batch spliced alignment and sequence indexing. Bioinformatics. 2011;27(13):1869-70.

54. Slater GS, Birney E. Automated generation of heuristics for biological sequence comparison. BMC Bioinformatics. 2005;6:31.

55. Holt C, Yandell M. MAKER2: an annotation pipeline and genome-database management tool for second-generation genome projects. BMC Bioinformatics. 2011;12:491.

56. Trapnell C, Hendrickson DG, Sauvageau M, Goff L, Rinn JL, Pachter L. Differential analysis of gene regulation at transcript resolution with RNA-seq Nat Biotechnol. 2013;31(1):46-53.

57. Conesa A, Gotz S, Garcia-Gomez JM, Terol J, Talon M, Robles M. Blast2GO: a universal tool for annotation, visualization and analysis in functional genomics research. Bioinformatics. 2005;21(18):3674-6.

58. Lohse M, Nagel A, Herter T, May P, Schroda M, Zrenner R, Tohge T, Fernie AR, Stitt M Usadel B. Mercator: a fast and simple web server for genome scale functional annotation of plant sequence data. Plant Cell Environ. 2014:37(5):1250-8.

59. Thimm O, Blasing O, Gibon Y, Nagel A, Meyer S, Kruger P, Selbig J, Muller LA, Rhee SY, Stitt M. MAPMAN: a user-driven tool to display genomics data sets onto diagrams of metabolic pathways and other biological processes. Plant J. 2004;37(6):914-39.

60. Mafra V, Kubo KS, Alves-Ferreira M, Ribeiro-Alves M, Stuart RM, Boava LP, Rodrigues CM, Machado MA. Reference genes for accurate transcript normalization in citrus genotypes under different experimental conditions. PLoS One. 2012;7(2):e31263.

61. Livak KJ, Schmittgen TD. Analysis of relative gene expression data using real-time quantitative PCR and the 2(T)(-Delta Delta C) method. Methods. 2001:25(4):402-8.

62. Wang L, Wang S, Li W. RSeQC: quality control of RNA-seq experiments. Bioinformatics. 2012;28(16):2184-5. 